Madrygal. Revista de Estudios Gallegos

ISSN: 1138-9664

\title{
Relocen na Martináa os ollos de don Ramón. A serra da Martiñá nos ollos e no pensamento de Otero Pedrayo
}

\author{
Modesto Hermida García
}

Na extensa obra de Ramón Otero Pedrayo, a Martiñá aparece, en prosa e en verso, con certa insistencia e aparece con ben diversa funcionalidade: como topos, como linde, como ética e como estética climático-paisaxística, como soar de míticas teorías, como xeradora de certas rudas tipoloxías humanas. Todo ese plural discurso, case sempre apretadamente sintético, xorde do propio Otero Pedrayo, cando como xeógrafo, cando como historiador, cando como lírico gozador de ensoñacións e melancolías, pero xorde, tamén, do relato dalgún dos seus personaxes, verbigracia do exclaustrado de Oseira.

\section{A prosa}

En “Os pazos no serán”, capítulo primeiro de Os señores da terra (de Os camiños da vida, 1928) relátansenos e descríbensenos as maneiras e bonanzas do pazo da Seara, en Trasouto, e ó extender a vista cara á lonxanía vaise visualizando unha ampla demarcación con moi diversos matices entre os territorios coadxuvantes: ribeiras e bocarribeiras, fondais e altueiros, planaltos e terras meogas de chairas labrantías como son Os Chaus. Nese mirar lonxano topéñase cos lindeiros desta xeografía a modo de serras que abrigan ou refrescan pero, sobre todo, marcan territorio. Esta función ó norte corrrespóndelle á Martiña, a serra que se pode enxergar en plenitude pola aba sudeste, dende o lombo máis elevado que vai devalando cara á regata de Ricobelo, un devalo que se inicia na altitude das hortas e nos prados da aldea da Martiñá, ata se ensanchar e achairar en Ardesende, coas terras de Vilamarín ó leste. Neste caso, a Martiñá é paisaxe pero é tamén chanzo de demarcación, é cancela pechada na lonxanía onde se inicia o mencionado territorio que se alonga ata o Faro de Avión; ese territorio que, directa ou indirectamente, entrega todas as súas augas procedentes de vales e de montes ó Miño do Ribeiro, mediante o Avia, o Arenteiro, o Barbantiño e outros moitos de máis escaso caudal tales como o río dos Frades, o Oseira ou o Silvaboa.

Tamén no relato "A Santa Compaña", de Entre a vendima e a castañeira, de 1957, outra volta a Serra funciona como lindeiro, como elemento coutador de espazos para marcar unha das beiras dos territorios nos que cobraba rendas dona Anxelina, que chegaban, pola outra banda, ata o Río dos Frades e á torre do Formigueiro. Aínda nesta función cabe sinalar que na Guía de Galicia aparece a serra Martiñá como referencia para a localización de certos puntos das estradas de Ourense a Compostela e da bifurcación de Cambeo cara a Lugo; neste contexto fánsenos os correspondentes apuntes sobre Cea, sobre Oseira (ursaria), a terra de osos no noroeste da Serra na que, ó parecer, abundaban os castros.

Pero tamén en prosa se pode chegar á exaltación lírica, á descripción da beleza paisaxística, á expresión da sensible sentimentalidade. No artigo "Dende a solaina", do que carecemos de data da publicación no xornal Galicia de Vigo, esparexe don Ramón a vista ó seu arredor e atópase coas serras circundantes entre as que sobrancea para o seu engado a serra Martiñá que, sen deixar de ser lindeiro ó norde, é harmónica forma xeométrica, é lonxana sensación de friaxe con xeadas nas mañanciñas onde os lobos se ocultan entre as uces, é o sorriso dun sol pequeneiro e temesiño nos cumes con reais dificultades para se abaixar ós vales montesíos. A Martiñá é leda porque, segundo Otero Pedrayo, ten nome de aturuxo e 
as neves son hábito branco acorde co hábito do fraderío cisterciense de Oseira. No verán é azul e no outono o sol poente adormíñase, fai brochas coma un ancián á calor da lareira. A Martiñá, para o señor de Trasalba, é a que nos mostra o norde dos Chaos sobre terras de pan, castiñeiros e lameiros de Cea, e reivindícase como avangarda dos planaltos de Lugo e das súas brancas estadeas de vidueiros.

Do outro lado da Serra, nos fondais da aba noroeste, asenta o mosteiro de Oseira, unha paraxe que don Ramón non pode espreitar dende Trasalba pero si pode pensala, pode evocala dende o seu fondo coñecemento da historia e, sobre todo, pode ficcionar dende a imaxinación do exclaustrado, de tal maneira que en "Unha tertulia", capítulo VI de Os señores da terra, vaise relatando unha imaxinativa e mítica orixe do mosteiro moi anterior ás demostradas orixes históricas naqueles montes de toxeiras e carrasca, montes tamén de carqueixas, tan singulares de estructura, tan lanzais en casos de se veren amparadas pola abondosidade propia ou por outras vexetacións abrigadoras, tan propicias a facer excelente lume nas lareiras pero tan esquencidas de don Ramón, ou do exclaustrado, segundo como se mire, como esquencida é a mimosa condición das terras de cultivo e praderías, río abaixo, coutadas polo cercado; ese que exclúe e deixa na miseria agraria, monte arriba, a veciñanza dos poboados circundantes, tales como San Martiño, entre outros. En todo caso, Otero Pedrayo mostra o seu engado por Oseira e pola montaña, dun xeito semellante ó que nunha certa etapa mostrou o Noriega Varela das breves pucharquiñas e as miúdas floriñas nas penedías. Dende o exclaustrado postúlase o mito dunha orixe druída, dende un pobo moi envellecido, parte do que chegara da lonxana Eirín, que xa tan só contaba coa illada presenza dun mozo sabio, forte, humilde e loiro, do que se temía que estaba destinado ó martirio pero que foi quen de se encontrar co monstro, xa tamén avellentado, que vivira asulagado nas lagoas de Lamas e Aguada e que, enternecido pola sabiduría e destemida actitude do mozo, manifestou, naquela ocasión de se extinguir a súa caste amaldizoada, que eran os tempos chegados para se proclamar a relixión de Cristo, co recado de que tería de ser el o mozo novo que había cantar a primeira misa nesta serra esgrevia, templo dos druídas. Desta maneira, no pórtico que se había de construír cos ósos do dragón aportados polos campesiños, tería de nacer Oseira. Nótese que o monstro deforme e escamado, feito para espaventar os máis rexos paladíns do rei Artús, non se viu afectado das fórmulas máxicas dos celtas para matalo, pero Deus, que xa miraba polas terras galegas, levou a tal encontro o mozo druída para que puidese cumprir coa súa misión. Precisamente, non lonxe de por estas terras augachentas de Lamas, onde andaba o monstro asulagado en tempos tan lonxanos, segundo se nos conta en "A partida", capítulo IV de Os señores da terra, cousas da carlistada, posiblemente na feira do Coedo, digo eu, un día catro dun mes calquera, é onde se encontran e se recoñecen, sen pretendéreno, o finxido esmoleiro, o coxo e o Pedro, o que andaba na gabilla co nome de o Corda, xente do Torto de Santa Comba, aquel capitán da partida que pretendía conquistar, de primeiras, as terras de Cea, Amoeiro e O Carballiño, para dende tal conquista dar o salto a máis bastos territorios.

En "Esquemas e lembranzas de Oseira", artigo fragmentado en sentencias diversas e publicado en 1930 no núm. 463 de Vida Gallega, volta a Martiñá, volta Oseira a ser núcleo temático con diversas consideracións; a saber: Oseira outravolta en relación cos druídas, coa mutación do símbolo druídico, fouce do luar crecente, para se pousar ós pés da Virxe-Nai. Catro silenzos da noite de Oseira para harmonizalos co canto coral do Císter. A serra Martiñá leva na aba as arquitecturas de Oseira coma unha dona campesiña leva un mangado de flores. Dona Xoana de Castro, irmá de dona Inés, símbolo dos destinos de Galicia, petou ás portas de Oseira nunha noite do medievo. Sempre as neves da Martiñá vistas dende os Chaus lle son brancura penitente do Císter. Con toda a tristeza, para Otero Pedrayo, os anos da ruína (Mendizábal) foron para as pedras de Oseira un baño de natureza para espertaren máis fortes. Unha queixa pola centralización que fai dependente Oseira dun enxoito claustro castelán, evocando tamén unha eclipse de sol, como simboloxía, que en Oseira el viviu de neno. Lembrando o decreto de Mendizábal e as consecuencias para Oseira, dubida da épica regada de sangue de monxes pero afirma o bautismo de sangue labrega por feridas de balas de máuser. Oseira románico, barroco, ciclo pechado de sazóns históricas da arte galega, tal como nos campos co sol novo camiña a fartura das vendimas.

E para rematar con estas referencias da prosa oteriana, aínda nos resta por constatar una velada alusión entre negativa e poco positiva ás xentes martiñás, malia que representadas tan só nun personaxe anónimo, un estudante 
de teoloxía residente na pensión do Castellano en Ourense, con quen coincide Paio Soutelo, estudante de bacharelato, que observa no da parte da Martiñá a un paisanote bo e sinxelo, pero un miserias rudo e simplón. Todo isto relatado no capítulo VI de $A$ maorazga (de $O s$ camiños da vida), "A clase retórica".

\section{O verso}

Seguramente a estas alturas aínda se pode manter a opinión bastante xeralizada de que a produción poética de Ramón Otero Pedrayo, en comparanza con outros xéneros e no contexto da súa amplísima obra, non resulta moi extensa nin tampouco se viña considerando dun relativizado valor extraordinario. Con todo, dende que en 2010 se publica a colectánea Poesía (ed. Xesús Alonso Montero, Galaxia, 2010), a produción poética de Otero Pedrayo cobra a dimensión que realmente lle corresponde, unha dimensión que se agranda con algunha aportación en linguas diversas, como castelán, latín ou alemán, lingua esta última coa que practica máis nidiamente o fenómeno da alofonía, e tamén co considerable labor de versionar para o galego e, dunhas para outras entre si, poemas orixinais nas mencionadas linguas, ademais de engadir para este mester a lingua francesa.

Agora, na expresión poética, é onde podemos atopar un Otero Pedrayo máis implicado afectivamente, liricamente, co fenómeno xeográfico e simbólico da súa proximidade física e afectiva. O poema dende o que definitivamente temos que recoñecer o señor de Trasalba implicado coa serra da Martiñá, como panorámica visual, como entidade presente no pensamento e na memoria, como parte da súa xeografía afectiva e mesmo familiar, é o que titula, precisamente, "A serra da Martiñá", que se atopa entre as súas primeirísimas achegas poéticas (1925). Consiste este poema nunha tirada de versos a modo de oda que se estrutura formalmente en catro serventés sen marcar, nin mediante oportuna puntuación nin visible espacialización, cada unha das catro estrofas. Esta gabanza montesía aséntase máis que nada na descrición, na relación entre a terra, a sintética paisaxe, a xeoloxía e os fenómenos atmosféricos, así como alguna aproximación ós elementos máis próximos do universo; pero aséntase tamén na humanización desa realidade xeográfica cando lle adxudica a condición de testemuña, eternidade conferida, xa que logo, da nosa existencia en comparanza co alumear festivo de lonxanos folións. A Serra é tan eterna coma o mar, é forte pero esquiva nai, cualificación que supoñemos corresponde coa referencia da extrema climatoloxía, algo tan da maneira de sentila naqueles fondais máis mimosos dos seus amados Chaus. A gabanza final constrúese con prolongada alegoría, cunha longa e visionaria imaxe: “...na túa outura está o xenio dos ventos a cantar coa lira eterna da túa pedra dura".

No poema "Cea", xa de 1952, hai cousas, paisaxes e lembranzas. Como non podería ser doutra maneira, comeza coas loubanzas ó pan pero sen esquencer, supoño que en referencia ou evocación da serra, que é un pan en "feitura de monte e de montaña”. A máis directa cita á Martiñá faise cando a considera maorazga que ampara Cea, esa doncela feitiña. Non esquence tampouco Otero Pedrayo a súa iterada imaxe literaria, a súa comparanza do hábito albo do prior de Oseira coa serra cuberta de neve que se abaixa no escuro fume do lar.

$\mathrm{Na}$ tirada de coplas de diversa feitura rítmica, xa de 1975, dedicada ó seu terrón máis querido, Chaus de Amoeiro, onde se fai referencia a moi diversos puntos da contorna para mostrar o seu embeleso ante a avanzada cadencia dunha posta de sol, pero sen esquencer a néboa que asulaga a encosta barbantiñá, outra volta acode tamén á realidade da xeografía norteña para, en excelente metáfora, deixarnos dito que o día xa tan só perdura nunha esmola que relampa na Martiñá.

Para poñer cabo a estas glosas sobre oterianos traballos literarios referidos á Martiñá ou con mención desta serra e mais dos seus contornos e circunstancias, aínda cómpre facer un repaso polas diversas coplas, tamén de diversa factura, que compoñen a longuísima tirada titulada "Bocarribeira", que data de finais do ano 1955 e comezos de 1956. Nun diálogo entre as serras curmás, a modo de hilozoísmo xeográfico con motivos climáticos, pídelle a de Avión á Martiñá que achegue lume ó Paraño, "que pá bica do poente/ hai de acender de mañá”; outra humanización resulta cando o vento da Martiñá pousou nos soutos da Torre e, namorado de xesteira amarelecida, deixa orfa de amor a lúa como de azul quedará orfa a serra. De maneira particular, facendo uso dunha súa iterada imaxe cromático-climática, proclama ante a folerpa da Martiñá, que se abaixou a cubrir de brancor as touzas, o compromiso de casamento coa noviña boa moza de Bouzas.

Vigo, primeiros días de marzo de 2017 